\title{
Transport Mode Choice Based on Material Characters
}

\author{
Liu Ming
}

School of Economics and Management, Weifang University, Weifang, Shandong, China (wfuliuming @ 126.com)

\begin{abstract}
The different traffic modes have different economic characters. The traffic mode chosen must adapt to the demand characters of the material. The material cost value is considered in the paper. In the choice mode, the timely arrival and security are been expressed by costs quantitatively, so the mode is more legible.
\end{abstract}

Keywords - Transport Mode, Material Characters, Material Cost Value

\section{基于物资特性的运输方式选择研究}

\author{
刘明
}

淮坊学院经济管理学院, 淮坊, 山东, 中国

\begin{abstract}
摘 要 企业货物运输要在考虑企业整体利益和各种运输方式经济特性的基础上, 选择与物资的运输需求特性相匹配的运输方 式。文章在考虑物资成本价值的基础上, 将运达的准时性、安全性换算为成本来表示, 以总成本理论为基础建立运输方式选择模型, 使决策定量化，更直观。
\end{abstract}

关键词 运输方式, 物资特性, 物资成本价值

\section{1. 引言}

运输作为物流中的关键一环, 其总成本亦占到了物流 总成本的 35\%-50\%左右, 占商品价格的 $4 \%-10 \%$ 。运 输对物流总成本的节约具有举足轻重的作用, 运输方式的 选择直接影响到物流供应链的整体效率和效益, 所以科学 合理的选择运输方式至关重要。

一方面, 不同的运输方式有不同的特性, 不同的物资 也有不同运输需求特性, 两者要相互匹配。其二, 运输方 式的选择将影响到产品的价格、配送的准时性和商品抵达 时的质量情况, 而这些又将直接影响到顾客的满意程度。 第三, 企业选择运输方式时必须综合考虑运输费用、交货 速度、发货频率、运输工具的运载能力及其安全性和可靠 性。

所以, 运输方式的选择要以企业的总效益最大为目标。 然而, 传统的运输方式选择主要是依靠经验和主观判断, 往往仅仅把运费放在第一位考虑, 忽略了物资的特性。为 此, 本文以总成本理论为基础, 充分考虑物资特性, 构建 运输方式选择模型, 使决策更为科学合理。

\section{2. 物资运输需求特性分析}

物资运输需求特性可用物资成本价值和时间敏感度来 描述。

物资的成本价值, 与简单的价格不同, 是指所购商品 对企业产品的贡献程度以及对企业财务利润的影响程度。 做出这种衡量, 主要是为了更好地进行资源管理, 对于对 企业贡献大、对企业利润影响大的采购商品理应在采购战 略上给予高度重视, 保证供应, 对运输服务水平要求比较 高。影响物品重要性的各种因素有采购总量, 该物品采购 金额占总采购金额的比重, 该物品对产品质量的影响程度, 该物品短缺给企业带来的损失等。

时间敏感度主要指物资对运达时间准确性的要求, 他 的主要影响因素有市场情况, 物资短缺对生产的影响程度, 物资库存量、物资库存费用、货款机会成本等。对于急需、 鲜活易腐或生产必不可少的物资, 要求运达时间准确快速, 时间敏感度高; 而对于库存量大、延迟交货对生产影响较 小的物资, 如办公用品等, 则对运达时间要求比较宽松, 时间敏感度低。

潍坊学院博士科研基金支持（资助号：2013BS22） 
根据物资的时间敏感度和物资成本价值对物料运输需 求特性进行分析, 可得到物资特点及其运输需求特性矩阵 图, 如图 1 所示。

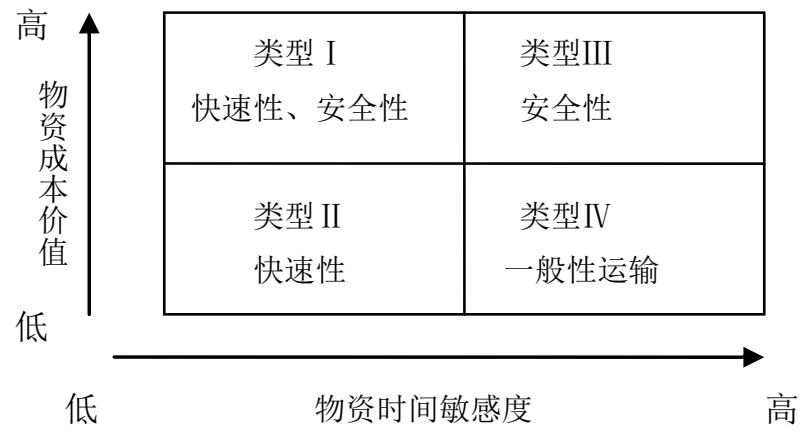

图 1 物资特点及其运输需求特性

（1）类型 I, 此类物资成本价值较高, 运达时间要求 短, 属于时间敏感物资, 如高价格鲜活货物, 要求运输快 速、安全。通常根据距离远近选择航空运输或者快递, 优 先考虑运输方式的快速性和安全性。
（2）类型 II, 此类物资成本价值较低, 但要求快速运 达, 需要快速、同时低成本的运输, 如报刊杂志、抢险救 灾物资等。所以在运输方式选择过程中要权衡成本与需求。

（3）类型III, 此类物资成本价值较高, 但是要求运达 时间比较宽裕, 如一些高附加值的电子产品等, 要求运输 安全、准时。可以在确保安全可靠的基础上根据运距和运 量, 选择汽车或者铁路运输。

（4）类型 IV, 此类物资成本价值较低, 而且要求运达 时间比较长, 属于一般性运输, 如一般货物如煤炭、钢铁、 矿建材料、粮食等。此类物资只需根据其运距和运量, 优 先考虑成本因素, 选择合适的运输方式既可。

\section{3. 各运输方式特性分析}

我国现代运输业由铁路、水运、公路、民航和管道等 五种运输方式组成。由于各种运输方式有不同的技术经济 特点, 一方面, 他们表现为优势互补、优劣交叉, 并存于 运输系统中; 另一方面, 在不同时空条件下, 表现为互相 间的协作、竞争、垄断等基本关系。表 1 列出了五种运输 方式的主要经济特性。

表 1 我国五种运输方式的主要运输特性

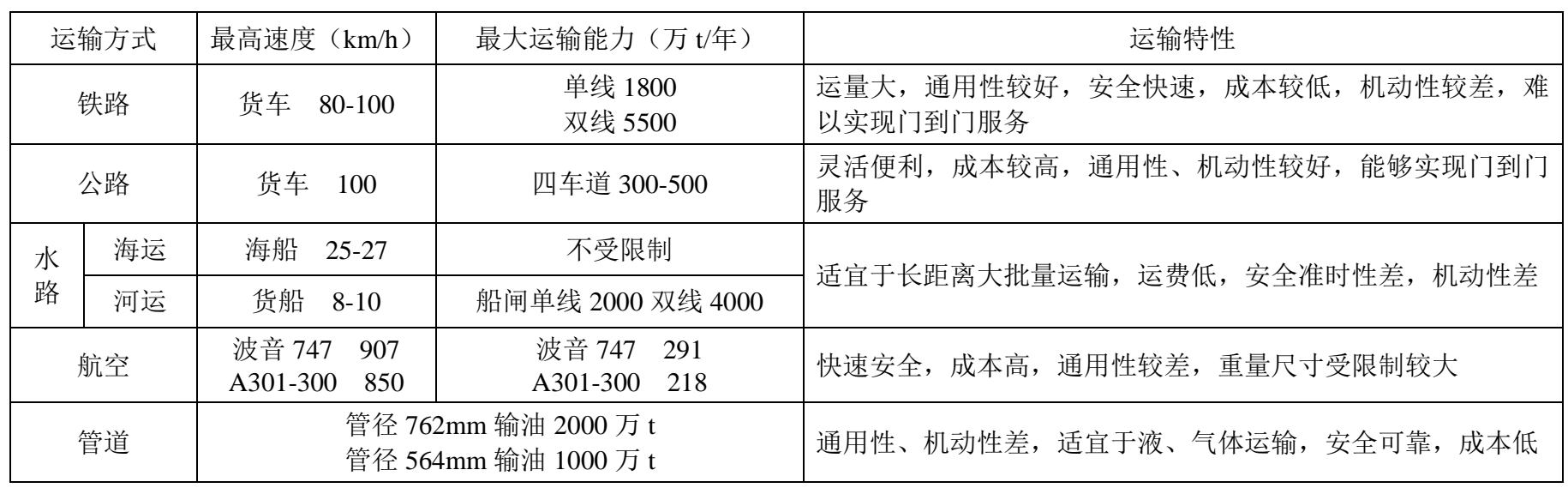

\section{4. 物资运输成本分析}

物资运输成本分为直接成本和间接成本。直接成本也 就是运费; 间接成本指由于运输方式的不同引起的其他费 用, 包括延迟交货费用、提前到货的库存费用、运输途中 的货物所占用资金的机会成本。

物料运输的总成本构成可用式 (1) 表示。

物料运输总成本 $=$ 直接成本 + 间接成本

$$
\begin{aligned}
= & \text { 运费+延迟交货费用+成本价值损耗 } \\
& + \text { 库存费用+货款机会成本 }
\end{aligned}
$$

\section{1 直接成本}

直接成本即运输费用。运输费用指物资在运输过程中 产生的成本, 我们用 $Y_{i}$ 表示运输方式 $i$ 的运输费用, 包括 基本运费和手续费等其他费用。

\section{2 间接成本}

(1) 成本价值损耗。在运输过程中, 必然会存在货损, 从而造成物资成本价值的损耗。成本价值损耗率描述了运 输的可靠性, 可以由式 (2) 确定: 
成本价值损耗率 $=\frac{\text { 运达时物资损耗价值 }}{\text { 运输物资总价值 }}$

（2）延迟交货费用。由于运输超过运达时间延迟交货， 产品或原材料不能得到及时供应, 造成客户需求得不到满 足、生产停止或者违反运输合同赔款等, 这时就产生了特 定费用一一延迟交货费用。在销售或配送环境下, 将会造 成失去销售机会, 甚至退货, 从而导致收益、利润和信誉 的损失。

(3) 库存费用。物资运输的准时性, 不仅仅是不能延 迟交货, 提前运达同样也会产生费用。物资提前送达时, 要产生库存费用。可以用单位库存费用与提前运达时间的 乘积表示。

（4）货款机会成本。货主往往把货物在途时间延长视 为一种损失。货物本身所占用的资金, 在延迟交货期间会 产生机会成本。货款机会成本的高低与企业所处行业密切 相关。

延迟交货费用、库存费用、货款机会成本, 描述了运 输的准时性要求, 体现了物资的时间敏感度特性。

\section{5. 物料运输模式选择}

\section{1 运输方式选择决策模型}

式 (1) 的总成本, 把运输的运费成本、安全性、准时 性等考虑因素都包含在内, 所以只需要选择总成本最小的 运输方式既可。目标函数如式 (3):

$$
\begin{aligned}
\min \eta & =\max \left(0, t_{i}-T\right) \cdot a+V \cdot \beta+\max \left(0, T-t_{i}\right) \cdot P \\
& +\max \left(0, t_{i}-T\right) \cdot \gamma+Y_{i}
\end{aligned}
$$

其中, $T$ 一要求运达时间

$t_{i}$ 一运输方式 $\mathrm{i}$ 的实际运达时间

$\alpha$ 一延迟交货成本

$V$ 一物资的成本价值

$\beta$ 一成本价值损耗系数

$P$ 一日库存成本

$\gamma$ 一单位物资所占用资金每日的机会成本

$Y_{i}$ 一运输方式 $i$ 的运输费用

$i$ 一铁路、公路、航空、水路、管道等运输方式
该模型, 通过对 $\alpha 、 \beta$ 系数的调整, 可以充分体现物资 的成本价值、时间敏感度等特性, 进而帮助企业选择物资 特性和运输方式特性相匹配的最佳运输方式。例如, 在机 会成本相当的前提下, 对于成本价值高且运达时间要求短 的物资, 其延迟交货成本 $\alpha$ 高且要求尽量减小成本价值损 耗系数 $\beta$, 所以, 应该尽可能选择准时、安全的运输方式; 反之, 对于成本价值低且时间敏感度低的物资, 其延迟交 货成本 $\alpha$ 小且成本价值损耗较小, 所以在选择运输方式时 更注重其运输费用。

\section{2 应用举例}

设现 $A 、 B 、 C$ 三种货物需要运输, 运输距离均为 $1000 \mathrm{~km}$, 其运输需求特性要求如表 2 所示。

\begin{tabular}{|c|c|c|}
\hline 物资 运输特性 & 运输量 & $\begin{array}{l}\text { 要求运达时间 } \\
\text { (天) }\end{array}$ \\
\hline A & $10 \mathrm{~kg} /$ 箱・40 箱 & 1 \\
\hline B & $60 t$ & 8 \\
\hline $\mathrm{C}$ & $5 \mathrm{~kg} /$ 件・20 件 & 3 \\
\hline 物资 运输特性 & $\begin{array}{c}\text { 每单位成本价值 } \\
\text { (元/单位) }\end{array}$ & $\begin{array}{l}\text { 日库存成本 } \\
\text { (元/单位) }\end{array}$ \\
\hline A & 1000 元/箱 & 15 元/箱 \\
\hline B & 1000 元/t & 10 元 $/ \mathrm{t}$ \\
\hline $\mathrm{C}$ & 1000 元/件 & 3 元/件 \\
\hline 物资 运输特性 & $\begin{array}{c}\text { 延迟交货成本 (元 } \\
\text { /单位・天) }\end{array}$ & $\begin{array}{c}\text { 机会成本 } \\
(\text { 元/单位・天） }\end{array}$ \\
\hline A & 50 & 6 \\
\hline B & 0.2 & 1 \\
\hline $\mathrm{C}$ & 8 & 10 \\
\hline
\end{tabular}

表 2 物资运输需求特性

通过表 2 可见, 物资 A 延迟交货成本和库存成本高, 要求准确的运达时间。物资 B 运输量大, 运送时间宽裕, 物资成本价值低。物资 $\mathrm{C}$ 单位成本价值和机会成本较高, 运送时间适中。

鉴于水运的运达时间较长, 管道运输的运输货品种类 限制, 在此, 仅比较公路、铁路和航空三种运输方式。表 3 列出了三种运输方式提供服务的经济特性, 包括运费、 运达时间、成本损耗系数。 
表 3 三种运输方式的经济特性

\begin{tabular}{|c|c|c|c|}
\hline \multirow{2}{*}{ 物资 } & \multicolumn{3}{|c|}{ 铁路运输 } \\
\hline & $\begin{array}{c}\text { 运费 } \\
\text { (元/单位) }\end{array}$ & $\begin{array}{c}\text { 运达时间 } \\
\text { (天) }\end{array}$ & $\begin{array}{c}\text { 成本值耗 } \\
\text { 损系数 }\end{array}$ \\
\hline A & 75 & 3 & 0.10 \\
\hline B & 60 & 8 & 0.02 \\
\hline $\mathrm{C}$ & 43 & 5 & 0.05 \\
\hline 运输特性 & \multicolumn{3}{|c|}{ 公路运输 } \\
\hline 物资 & $\begin{array}{c}\text { 运费 } \\
\text { (元/单位) }\end{array}$ & 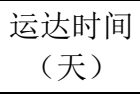 & $\begin{array}{c}\text { 成本值耗 } \\
\text { 损系数 }\end{array}$ \\
\hline $\mathrm{A}$ & 98 & 2 & 0.06 \\
\hline $\mathrm{B}$ & 80 & 4 & 0.03 \\
\hline $\mathrm{C}$ & 63 & 4 & 0.02 \\
\hline 运输 & \multicolumn{3}{|c|}{ 航空运输 } \\
\hline 物资 & $\begin{array}{c}\text { 运费 } \\
\text { (元/单位) }\end{array}$ & $\begin{array}{c}\text { 运达时间 } \\
\text { (天) }\end{array}$ & $\begin{array}{c}\text { 成本值耗 } \\
\text { 损系数 }\end{array}$ \\
\hline A & 150 & 1 & 0.02 \\
\hline $\mathrm{B}$ & 150 & 2 & 0.03 \\
\hline $\mathrm{C}$ & 120 & 1 & 0.01 \\
\hline
\end{tabular}

根据表 $2 、 3$ 的内容, 通过式 3 可以计算每单位货物不 同运输方式下的单位物资的运输总成本 $\eta$, 进而通过比较 选择恰当的运输方式，如表 4 。

\section{表 4 物资运输方式选择结果}

\begin{tabular}{|c|c|c|c|c|}
\hline 项目 & 昳路运输 & 公路运输 & 航空运输 & 选择结果 \\
\hline A (元/箱) & 337 & 214 & 170 & 航空 \\
\hline B (元/t) & 80 & 150 & 240 & 铁路 \\
\hline C (元/件) & 129 & 101 & 136 & 公路 \\
\hline
\end{tabular}

根据结果, 以 $\mathrm{A}$ 物资为例分析。 $\mathrm{A}$ 物资三种运输方式 的运费由高到低分别为航空、公路。铁路。但是由于公路 和铁路运输不能准时送达, 不满足 $\mathrm{A}$ 物资的特性, 导致了 较高的延迟交货成本, 所以, $\mathrm{A}$ 物资选择航空运输的运输
总成本最低。这验证了模型的有效性, 也进一步说明了物 资运输方式的选择不能仅仅考虑运费, 要从系统最优的角 度综合考虑企业的整体利益, 选择适合特定物资的运输方 式。

\section{6. 结论}

科学地进行运输方式选择的决策, 首先要分析物资的 运输需求特性, 然后寻找与其需求相匹配的运输方式。本 文以总成本理论为基础, 充分考虑物资特性, 构建运输方 式选择模型, 综合考虑运费、运输的安全性、准时性和企 业的盈利性，使得决策更为规范和合理。

\section{参考文献(References)}

[1] Hu Song-ping, "Strategy for transport mode choice", Logistics Management, vol. 25, no. 9, pp. 6-10, 2002.

[2] Shen Chi-yun, "Traffic and Transportation Engineering", BeiJing: China Communications press, pp.3-4, 2002

[3] Chen Yang, Zhou Xiaohua and Ye Huaizhen, "Research on the choice of transport mode based on the characteristics of the transportation demand", Railway Freight Transport, no. 4, pp. 14-17, 2010.

[4] Wu Qunqi, Chen Wenqiang, Zhang Shengzhong. "Study on the essence and characteristics of transport demand", Railway transportation and economics, vol. 31, no. 4, pp. 32-36, 2009

[5] Zhang Jun and Han Zhengbao, "Transport Modes Selection of Multimodal Transport Based on the Minimum Total Cost", Value Engineering, no.8, pp.43-45, 2014.

[6] Fan Fanglai, "The Pain of Fog and Haze-research for the Selection of Green Logistics Transportation Models", Logistics Sci-Tech, no.2, pp.102-104, 2014-7-21

[7] Liu Ming and Zhu Guangsheng, "Study on development of logistics enterprises that rely on the railway transportation", Railway transportation and economics, vol. 28, no. 11, pp. 55-57, 2006.

[8] Rommert Dekker, Jacqueline Bloemhof, Ioannis Mallis, "Operations Research Green logistics-An overview of aspects, issues, contributions, and challenges", European Journal of Operational Research, vol.219, pp.671-679, 2012. 